\title{
Reminiscencias misóginas en la literatura ejemplar: un aspecto de lo maravilloso mágico en la Baja Edad Media
}

\author{
Graciela Cándano
}

\begin{abstract}
Este artículo propone un breve recorrido por las representaciones de la mujer como objeto de sospecha, tanto en situaciones cotidianas registradas en la legislación canónica, como en concepciones relacionadas con el fenómeno de lo maléfico sobrenatural que lleva a ver al sexo femenino como representación del diablo. Se presenta, finalmente, una serie de calas en la tradición de los exempla, donde los personajes de la mujer y del diablo son intercambiables.
\end{abstract}

Palabras Clave: mujer medieval, literatura ejemplar, brujería, diablo, $M a$ lleus Maleficarum

This paper reviews the different representations of women as suspects of evil making, both in every day life situations registered in canonic legislation and in supernatural events. This review intends to explain why women were associated with the devil and analyzes a series of exempla where the characters of the devil and a woman are interchangeable. 

Graciela Cándano

Instituto de Investigaciones Filológicas, UNAM

\section{Reminiscencias misóginas en la literatura ejemplar: un aspecto de lo maravilloso mágico en la Baja Edad Media}

...el hecho más inquietante de lo maravilloso medieval [probablemente sea] que nadie se interroga sobre la presencia que no tiene vínculo con lo cotidiano y que sin embargo está por entero inmersa en lo cotidiano.

JACQUES LE GoFF

Autores como Jacques Le Goff y Frantisek Graus han establecido que durante la Alta Edad Media la Iglesia tuvo la pretensión de transformar, ocultar y hasta destruir oficialmente uno de los elementos más peligrosos y más seductores de la cultura pagana: lo maravilloso, aquello que se asocia a los mirabilia, es decir, objetos mágicos, monstruos, animales imaginarios, proezas, castillos encantados (Le Goff, Lo maravilloso, 11-20). Sin embargo, a partir de los siglos XII y XIII surge libremente lo maravilloso en la cultura y en la sociedad. ${ }^{1}$ Es la pequeña y la mediana nobleza, la caballería —una clase ascendente pero

${ }^{1}$ Digo libremente porque, de modo privado y clandestino, muchos mitos y no poco de lo ultraterreno no cristiano nunca abandonaron el imaginario de la población medieval. 
amenazada —, la que opone a la cultura eclesiástica, asociada a la alta nobleza, las novelas cortesanas y todo el hechizo del prodigio.

En la cultura popular, lo maravilloso irrumpe básicamente en las alas reductivas del milagro, lo miraculosus, propuesto por la Iglesia a través de autores como Gonzalo de Berceo (h.1198-1264), o el anónimo poeta que recreó la vida de santa María Egipciaca; esta oferta contiene derivaciones simbólicas y moralizadoras: lo maravilloso (mirabilia y miraculosus) se ha recuperado plenamente. Pero hay otras razones que influyeron en el Bajo Medioevo para que hicieran su aparición y reaparición ideas fantasiosas de orden sobrenatural maléfico (magicus) sobre lo cotidiano. Entendiendo lo sobrenatural maléfico como lo relacionado con el diablo, con el mal, ${ }^{2}$ en este trabajo me propongo exponer algunas manifestaciones documentadas del fenómeno magicus, como expresión particular de lo sobrenatural.

En los siglos XII y XIII, así como en los principios del XIV, se permitió a ciertas mujeres de naturaleza excepcional desenvolverse autónomamente hasta cierto punto. Celebridades como Hildegarda de Bingen (1098-1179), ${ }^{3}$ Eloísa (1101-1164), Leonor de Aquitania (1122-1204) o Blanca de Castilla (11881256) — quienes reclamaron e hicieron firme uso de sus dones de mando y mostraron independencia de criterio-, suscitaron en dominios eminentemente clericales un temor proveniente de

\footnotetext{
${ }^{2}$ María José Rodilla aclara que lo maravilloso mágico no se debe únicamente a la acción de las fuerzas malignas, sino a las representadas por hadas, ninfas y otros seres benévolos (Lo maravilloso medieval, 77-78). Me referiré aquí sólo a las fuerzas desatadas por las brujas, vistas como potencias del mal.

3 "La influencia del pensamiento y la obra de Hildegarda marcaría en los siglos siguientes [...] una pauta para la expresión de la autorrepresentación femenina en el marco de la literatura europea, cuyos resultados se vislumbrarían en el contexto de las autobiografías" (cfr. Arauz Mercado, "Imagen y palabra", 215). Y posiblemente las mujeres místicas e iluminadas se verían reflejadas, siglos después, en las denominadas "alumbradas" de la época colonial (ver Méndez, "Ilusas e iluminadas", 41-51).
} 
la idea de que, precisamente a causa de sus virtudes, tales mujeres y sus emuladoras podrían constituir una amenaza u oposición real a la supremacía del varón sobre el mundo conocido. Y ese miedo, ese recelo, se fue extendiendo y multiplicando, ya convertido en fobia, incluso hacia las más humildes campesinas de toda Europa, "desde Finlandia hasta Italia, desde Escocia hasta Rusia", señalan Bonnie Anderson y Judith P. Zinsser (Historia de las mujeres, 186). Dice Philippe Ariès al respecto: "es posible que durante la Edad Media la desconfianza hacia la mujer haya aumentado entre los hombres y, en particular, entre los clérigos, como una especie de reacción de defensa ante la importancia que había adquirido la mujer" ("San Pablo", 67). Estas circunstancias se conjugaron, deplorablemente, con arraigados atavismos, tales como la creencia de que la magia y las fuerzas sobrenaturales existían y de que la mujer estaba esencialmente vinculada a ellas. A partir del siglo XII al XIV, tanto en Florencia como en Roma o en París, las mujeres fueron acusadas de despertar la impotencia o la lujuria a los hombres con sus brebajes (Kieckhefer, European Witch, 28). ${ }^{4}$

Ahora bien, acorde con las tendencias antihechiceriles, el Arcipreste de Talavera, insigne cronista de su tiempo, además de incisivo moralista (primera mitad del siglo xv), refiriéndose a las mujeres que desean atrapar a un hombre en sus redes amorosas, dice en tono didáctico:

Comiençan a fazer [...] fechizos, encantamientos e obras diabólicas más verdaderamente nombrados, e ellas dízenles byenquerencias. Desto son causa las viejas matronas, malditas de

${ }^{4}$ Existen pruebas parciales de que en el siglo xIV comenzó a desatarse masivamente la leyenda brujeril pública, pues se celebraron unos 500 procesos contra mujeres sospechosas de practicar la magia negra en Alemania, Francia, Suiza (cfr. Anderson y Zinsser, Historia de las mujeres, 186-188). El primer juicio en que una mujer fue llevada a la picota por haber adquirido su maléfico poder mediante relaciones sexuales con un íncubo tuvo lugar en Irlanda, entre 1324 y 1325 (Riquer, "Brujas e identidad", 342). 
Dios e de sus santos, enemigas de la virgen Santa María [...]; e entonce toman oficio de alcayuetas, fechizeras e adevinadoras, por fazer perder las otras como ellas. ¡O malditas, descomulgadas, disfamadas, traydoras, alevosas, dignas de byvas ser quemadas! ¡Quántas preñadas fazen mover, ${ }^{5}$ por la venganza del mundo...! (Martínez de Toledo, Corbacho, 171 y 172). ${ }^{6}$

Sin embargo, un fenómeno que rebasaba en malignidad a la semejanza con Luzbel, el trato carnal con éste o la posesión satánica, era la condición de la mujer como vehículo ideal escogido por el demonio para dañar al hombre; el que la mujer fuera, tal como lo describía Anselm de Turmeda en 1398 en su Llibre de bons amonestaments, lo siguiente:

La mujer es principio de pecado, navío del perverso Satanás.

(apud, La vida, Riu, 383).

A fines del siglo XV se complicaron las cosas para la mujer, pues, a raíz de la bula pontificia Summis desiderantes affectibus, de 1484, en la que el papa Inocencio VIII instaba a la policía inquisidora a combatir un supuesto culto satánico que se estaba generalizando en los obispados alemanes, se creó, dos años después, el "manual del perfecto cazador de brujas", el Malleus maleficarum (o Martillo de brujas), escrito a solicitud del propio Inocencio por los clérigos Henry Kraemer y Jacob Sprenger. El hecho es que las víctimas fundamentales de la bula y del libro fueron las personas dedicadas a aplicar tratamientos médicos, es decir, las yerberas y, singularmente, las parteras, sapientes mujeres que conservaban la dilatada tradición asociada a la procuración del buen alumbramiento, pero también a los recién satanizados ejercicios de la anticoncepción y el abor-

${ }^{5}$ Fazen mover: hacen abortar.

${ }^{6}$ El énfasis es mío. 
to $^{7}$-y de otros casos asociados a la procreación - por medio de pociones elaboradas con hierbas medicinales. ${ }^{8}$ Romermann indica que "las mujeres viejas, expertas en el oficio ginecológico y las bebidas afrodisiacas, fueron globalmente condenadas a muerte con una sola frase: 'Nadie perjudica más a la religión católica que las parteras"” (Romermann, "La matanza", 4).

Estas curanderas fueron, pues, tildadas de brujas, y, en una época en que se creía que Satanás había sido condenado al Infierno por haber tenido relaciones sexuales con las hijas de los hombres (Rubial, Las metáforas del cuerpo, 115), era consecuente que también se les tachara de relacionarse con el demonio. La sistemática campaña de desprestigio orientada a su exterminio — que arrastró a muchas otras mujeres que representaron un peligro para el poder político y eclesiástico- alcanzó

${ }^{7}$ La mismísima Hildegarda recomendaba, en el siglo XII, un remedio contra el aborto, preparado con leche de vaca o de oveja y ramitas de ojaranzo o carpe (Schiller, Remedios naturistas, 68). Lo que nos podría llevar a preguntarnos si esta sabia en la ciencia curativa y naturista no conocería también recetas que pudieran ser utilizadas como abortivos. Recordemos que en el siglo XI la culta y noble dama llamada Trótula, ligada a la Escuela Médica Salernitana y autora del primer tratado sistemático sobre ginecología — atribuido a una mujer-, conocido como $D e$ passionibus mulierum ante, in et post partum, daría ciertas pautas al respecto en el capítulo XI: "Cómo impedir o favorecer la concepción". Ferruccio Bertini nos da noticias de ello: "También estaba informada sobre las causas de la esterilidad [...]. Sin embargo, sistemas anticonceptivos que [se] mencionan son legado de una medicina popular de tipo mágico-brujesco, pero de dudosa eficacia, ya se trate de llevar sobre la carne desnuda un útero de cabra virgen, de colgarse al cuello o de tener en la boca una piedra llamada gagates, de albergar en el pecho los testículos de un macho de garduña envueltos en piel de ganso, o de insertar unos granos de cebada" (Bertini, "Trótula la médico", 148-149).

${ }^{8}$ El papa Gregorio IX, en el siglo xIv, había condenado este tipo de prácticas en las Decretales. "En esta obra se establece que se tendrá por homicida a aquel que procure un aborto y al que hace o administre sortilegios o venenos de esterilidad. Si por causa de alguno, sea por pasión o con maliciosa reflexión, sea hombre o mujer, realiza algún sortilegio o administra veneno por el cual se impida engendrar así como concebir o dar descendencia, se tendrá por homicida" (Pérez de Arce Molina, "Configuración histórica", artículo 14). La decretal Si aliquis dice al calce: "Si alguno por odio o por fazer luxuria, fiço algo a omne o a muger, o dio a bever por que non pudiesse engendrar, nin naçer generation, sea iudgado por omicida" (Decretales, 1940, Libro V, título XII, capítulo V, 166). 
a miles de miembros del género femenino, hasta que fue quemada la última sentenciada en 1782: una empleada doméstica suiza (Cohn, apud Riquer, "Brujas e identidad", 349-359).9

Independientemente de casos particulares, lo que hay que remarcar es que tal parece que las sospechosas eran ajusticiadas en la hoguera o mediante la tortura, el degollamiento, el estrangulamiento, la descuartización, la horca o la grotesca "prueba de agua". En esa revuelta atmósfera, las mujeres, con sus remedios tradicionales, arcaicos sortilegios o salmos ancestrales — todos ellos ajenos a los poderes oficiales-, parecían confabularse a fin de coadyuvar en la vacilación y el caos. Las curanderas y comadronas (y desde luego las alcahuetas, virgueras - las que restituían la virginidad o hacían virgos - , barraganas, adivinas ladronas, prostitutas, perfumistas, viudas, ermitañas, limosneras y un sinfín de campesinas analfabetas y más bien ancianas) terminaron, pues, siendo consideradas hechiceras y brujas, agentes del demonio y, en la delirante fantasía popular, hasta oficiantes de sucios ritos bajo diabólicos altares. ${ }^{10}$

Ocasionalmente, las mujeres - y los hombres — sí llegarían a perpetrar aquelarres y misas negras y a cometer crímenes con un claro contenido erótico, sintiéndose verdaderamente poseídos por Satanás (como sucedió en los cruentos prados de Berroscoberro). Al diablo, que supuestamente se hacía presente en esos cultos, se le veía como un monstruo sexual caza mujeres, de ahí que el dominico bretón Alain de la Roche (quien difundió el uso del rosario hacia 1428) viera al demonio - anota Johan Huizinga - con repulsivas partes sexuales de las que surgía un río de fuego y azufre que, con su humo, oscurecía la Tierra (Huizinga, El otoño, 312).

\footnotetext{
${ }^{9}$ Las estimaciones del rango de este sacrificio masivo varían entre 9 millones y 40 mil mujeres asesinadas (cfr. Romermann, "La matanza", 1-6).

${ }^{10}$ Coherentemente con ello, recuérdese que Sempronio, refiriéndose a la más célebre alcahueta y virguera de la literatura española, dice en el acto I: "Celestina, hechicera, astuta, sagaz en cuantas maldades hay" (Rojas, La Celestina, 59).
} 
William Monter (Witchcraft in France, 156-157) refiere el siguiente caso documentado, acontecido en 1539: Jeanette Clerc, llevada a los tribunales por su vecino - como consecuencia de que éste había sufrido un daño: había perdido su vaca-, después de la tortura "confesó" lo que la Inquisición ginebrina esperaba: ella montaba sobre una escoba y volaba hasta la sinagoga, acompañada por un demonio llamado Simón; con él practicaba el sexo contranatura, su semen era helado y la cicatriz que tenía en su rostro provenía de un mordisco dado por ese ser diabólico; ingería manzanas, pan blanco y vino blanco en los aquelarres, y celebraba satánicas reuniones los jueves y los viernes.

Este tipo de horrendas declaraciones forzadas y recabadas mediante la palabra escrita incluían la fornicación con animales, bestias imaginarias o sapos ataviados con ropajes fantásticos; conversaciones con infantes fallecidos o asesinatos y devoramientos de éstos antes del bautismo; profanación reiterada de la hostia y otros géneros de gravísimas herejías; transformaciones y metamorfosis diversas: provocación de tempestades y plagas; impotencia masculina u odio entre personas; ilusión de que se ha perdido el miembro viril; derrotas en las guerras, y la consabida elaboración de ungüentos y pócimas con todo tipo de substancias nauseabundas, como excrementos y putrefacciones. ${ }^{11}$ En otras palabras, existía en el imaginario medieval la necesidad de mantener a raya al Maligno y transferir sus faltas y culpas morales (manifiestas en los señalados castigos de Dios) a la enemiga número uno: la mujer, la perversidad universal, el mismísimo demonio apoderado de su genio y figura.

${ }^{11}$ Hasta los mirabilia parecen hacer acto de presencia en este torrente de $m a$ gicus. 


\section{Los exempla y la mujer}

Un ejemplo documentado de esta iniquidad lo brinda Castigos e documentos para bien vivir ordenados por el rey don Sancho $I V$, texto elaborado de 1292 a 1293 por un equipo de eruditos clérigos que acompañaron al rey don Sancho en algunas campañas militares. La obra, estructurada mediante el recurso del padre que amonesta a su hijo (un espejo de príncipes), desarrolla toda una teoría de valores espirituales cristianos y promueve el interés por las prácticas religiosas. Su leitmotiv es el no tomar el mal camino como consecuencia de dejarse llevar por el demonio, el mundo y la carne. ${ }^{12}$ Veamos el exemplum: un viejo ermitaño lleva treinta años de soledad y de alimentarse con agua y yerbas del monte. Pesándole al diablo un hombre tan casto y frugal, decide aparecérsele a la entrada de su cueva, un día de intenso frío, con la forma de una niña hermosa, huérfana, hambrienta y extraviada. El eremita, que siente afecto por todas las criaturas de Dios, la ampara, le da un poco de pan y la cubre con un tosco manto de pieles. Después de comer, ella rompe a llorar con gran desconsuelo, por lo que el ermitaño comienza a mirarla más a menudo, a hablarle y a acercarse a ella con ternura. La cálida e íntima situación provoca que se besen, y que el viejo desee "su voluntad cumplir a más". De pronto

la muger çerca de sí desfízose entre manos. ${ }^{13} \mathrm{E}$ el diablo saltó ençima de vna viga en semejança de cabrón e començó a reyrse a grandes risadas e fazié escarnio del hermitanno [...]. E el diablo le dizié: "Mesquino, para mientes cómmo te sope yo engañar e cómmo te fiz perder en vna ora los treynta annos que has pasados" (Castigos, 177-178).

${ }^{12}$ Simultáneamente a Castigos e documentos aparecieron obras político-morales del mismo corte como el Libro del consejo y de los consejeros.

${ }^{13}$ La mujer que estaba a su lado se desvaneció entre sus manos. 
Esta es una de las concepciones más negativas posibles que se puede tener de la mujer, y es una imagen más o menos común en el Medioevo: un magicus evidente. "El diablo toma forma de mugier, por que a los buenos pueda enpesçer", ${ }^{14}$ reza el epígrafe de un exemplum para predicadores tomado del $\mathrm{Li}$ bro de los exemplos por a.b.c. (105). Esta colección de exempla compuesta por el religioso Clemente Sánchez de Vercial entre 1400 y 1421 fue la más monumental de todas, pues llegó a contener hasta 540 pequeños relatos, aptos para ser utilizados en el sermón habitual de los domingos o en la prédica de los monjes mendicantes. En la narración 115 (Sánchez de Vercial, Libro de los exemplos, 44) se observa que el diablo es susceptible de presentarse, no sólo como hermosa doncella, sino como una anciana que parece ser buena persona, pasando así por todos los tipos de mujeres según la oportunidad.

Por lo tanto hay que estar atentos y atemperarse, pues el hombre puede ser seducido o atacado en cualquier momento por su demoníaca enemiga, la mujer. "Sed sobrios y velad — dice Pedro en su primera epístola (5:8)—, porque vuestro adversario, el diablo [...] anda alrededor buscando a quien devorar."

En seguida me referiré a un relato en el cual la mujer es una verdadera diabla, un súcubo. El que la mujer y el diablo sean la misma cosa es el hecho maravilloso mágico más extremo que puede encontrarse en la Baja Edad Media con relación al tema que me ocupa. Recurriré a la colección de exempla de mi predilección, Sendebar, también conocida como Libro de los engannos e assayamientos de las mugeres. La traducción al castellano de esta obra de procedencia india fue auspiciada a mediados del siglo XIII por Fadrique, hermano de Alfonso X el Sabio. Uno de sus exempla dice lo siguiente: un príncipe, cabalgando por el monte, se encuentra a una moza que — según ella dice_ - también se hallaba perdida. El joven se compadece

${ }^{14}$ Enpesçer: hacer daño. 
de la joven y la sube a la grupa de su caballo. Cabalgan hasta llegar a una aldea abandonada. Ahí la moza baja de la bestia y penetra en una casa ruinosa... "E quando vio el niño que tardava, desçendió de su caballo e subió en una pared e paró mientes e vio que era una diabla que estava con sus parientes" (Sendebar, 97). La moza — la diabla, el abominable súcubo- quería extorsionar al Infante por suponerlo rico, hijo de rey.

Otro de tantos ejemplos de esta índole lo brinda cierta escena de tentación diabólica representada en un capitel del siglo XII de la iglesia de la Madeleine de Vézelay, en la que se ve a Satanás ofreciéndole una mujer a san Benedicto. Las descripciones de la época se refieren al trío de los personajes, de derecha a izquierda, como sanctus Benedictus, diabolus y diabolus (apud Frugoni, "La mujer en las imágenes", 421), respectivamente intercambiables. Las reminiscencias ${ }^{15}$ son como las herencias: se encuentran, no se crean y... como dice Le Goff, "esa herencia obliga a un esfuerzo para aceptarla o modificarla o rechazarla tanto en el nivel colectivo como individual" (Le Goff, $L o$ maravilloso, 10).

He aquí algunas muestras de lo maravilloso mágico de los siglos XIII al XV, integradas con naturalidad, no sólo en el ámbito cotidiano de una población ávida de sucesos sobrenaturales, sino también en el ambiente polifacético de los exempla, donde a la mujer se le vincula con las fuerzas maléficas. ¿Reminiscencias de las mujeres que vivieron fuera del orden "natural" exigido al sexo femenino por la sociedad medieval?

En definitiva, podemos concluir que la connotación marcadamente sexual de la expresión diaboli ianua de Tertuliano tuvo gran fortuna en la mentalidad colectiva y en la memoria permanecía la emblemática imagen de la mujer como instrumentum diaboli (Bertini, La mujer medieval, 19).

${ }^{15}$ Reminiscencia: acción de representarse u ofrecerse a la memoria el recuerdo de algo que pasó. Pero también se puede considerar como la facultad del alma con que se trae a la memoria aquellas imágenes que se han olvidado o confundido. 


\section{REFERENCIAS}

Anderson, Bonnie y Judith P. Zinsser, Historia de las mujeres: una historia propia, vol. 1, Barcelona, Crítica, 1992.

Arauz Mercado, Diana, "Imagen y palabra a través de las mujeres medievales (siglos IX-XV)", Escritura e Imagen, 1, 2005, 199-220.

Ariès, Philippe, "San Pablo y (los pecados de) la carne", en Sexualidades occidentales, Philipe Ariès et al. (dir.), México, Paidós, 1987, 65-69.

Bertini, Ferruccio, "Trótula la mística”, en La mujer medieval, Ferruccio Bertini (ed.), Madrid, Alianza, 1991, 131-152.

CÁndano, Graciela, La harpía y el cornudo, México, Universidad Nacional Autónoma de México, Instituto de Investigaciones Filológicas, 2003 (Cuadernos del Seminario de Poética, 20).

Caro Baroja, Julio, Las brujas y su mundo, Madrid, Alianza, 1979.

Castigos e documentos para bien vivir ordenados por el rey don Sancho IV, Agapito Rey (ed.), Bloomington [Indiana], Indiana University, 1952 (Humanities Series, 24).

Decretales de Gregorio IX, Jaime Mans Puigarnau (ed.), Madrid, 1940.

Deyermond, Alan, Historia de la literatura española. La Edad Media, Barcelona, Ariel, 1973.

Dillard, Heat, Daughters of the Reconquest, Cambridge, University Press, 1989.

Duby, Georges, El caballero, la mujer y el cura, Madrid, Taurus, 1982.

_- El amor en la Edad Media y otros ensayos, Madrid, Alianza, 1990.

_ Mujeres del siglo XII, Santiago de Chile, Andrés Bello, 1996.

FRUGONI, Chiara, "La mujer en las imágenes, la mujer imaginada", en Historia de las mujeres en Occidente, t. 2, La Edad Media, Georges Duby y Michelle Perrot (dir.), Madrid, Taurus, 1992, 419-467.

Fumagalli, María Teresa, "Eloísa la intelectual", en La mujer medieval, Ferruccio Bertini (ed.), Madrid, Alianza, 1991, 153-176.

Huizinga, Johan, El otoño de la Edad Media, Madrid, Selecta de Revista de Occidente, 1973. 
KIECKHEFER, Richard, European Witch Trials: Their Foundations in Popular and Learned Culture, 1300-1500, Berkeley, University of California Press, 1976.

Kors, Alan C. y Edward Peters, Europe 1100-1700: A Documentary History, Philadelphia, University of Pennsylvania Press, 1978.

LE GoFF, Jacques, Lo maravilloso y lo cotidiano en el Occidente medieval, Barcelona, Gedisa, 1985 (Serie Mediaciones, 12).

LeONARDI, Claudio, "Catalina la mística", en La mujer medieval, Ferruccio Bertini (ed.), Madrid, Alianza, 1991, 203-226.

Libro del consejo y de los consejeros, Agapito Rey (ed.), Zaragoza, Biblioteca del Hispanista, 1962.

Libro de los exemplos por a.b.c., John Esten Keller (ed.), Madrid, Consejo Superior de Investigaciones Científicas, 1961.

Martínez de Toledo, Alfonso, Arcipreste de Talavera o Corbacho, J. González Muela (ed.), Madrid, Castalia, 1970.

McKey, Jameson, Vida de Satanás. Una biografía del diablo, Barcelona, Plaza \& Janés, 1963.

MéndeZ, María Águeda, "Ilusas e iluminadas: ¿discurso místico o erótico?", en Secretos del Oficio: avatares de la Inquisición novohispana, México, El Colegio de México-Universidad Nacional Autónoma de México-Consejo Nacional de Ciencia y Tecnología, 2001, 41-51.

MonTER, E. William, Witchcraft in France and Switzerland: The borderlands during the Reformation, Ithaca [New York], Cornell University Press, 1976.

NATHÁN BRAVO, Elia “¿Quiénes eran las brujas?”, en Palabra e imagen de la Edad Media (Actas de las IV Jornadas Medievales), Lilian von der Walde, Aurelio González (eds.), México, Universidad Nacional Autónoma de México, 1995 (Publicaciones Medievalia, 10).

Pérez de Arce Molina, Ricardo, "Configuración histórica del delito de aborto en el derecho canónico desde los primeros siglos del cristianismo hasta el código de 1983 y su desarrollo", ARS Medica, Revista de Estudios Médico Humanísticos 6:6 (s.f.), Universidad de Chile, <http://escuela.med.puc.cl/publ/ArsMedica. html>. [Consulta: 11 de marzo de 2009.]

Power, Eileen, Gente de la Edad Media, Buenos Aires, Editorial Universitaria de Buenos Aires, 1966. 
REINHARD, Wilthelm, Historia de la población mundial, Rosario [Argentina], Comisión de Educación Estadística del Instituto Interamericano de Estadística, 1959.

Riquer, Florinda, "Brujas e identidad femenina (Saber, poder y sexualidad)", en Trabajo, poder y sexualidad, México, El Colegio de México, 1989, 331-358.

Riv, Manuel, La vida, las costumbres y el amor en la Edad Media, Barcelona, De Gassó Hnos., 1959.

Rodilla León, María José, Lo maravilloso medieval en El Bernardo de Balbuena, México: Universidad Nacional Autónoma de México-Universidad Autónoma Metropolitana Iztapalapa, 1999 (Publicaciones Medievalia, 20).

Rojas, Fernando de, La Celestina, Bruno Mario Damiani (ed.), México, Real Editorial Iberoamericana, 1987 (Letras Hispánicas, 4).

Romermann, Birgit, "La matanza de miles de 'brujas' medievales", Excelsior (de Der Spiegel de Hamburgo), trad. Herdis Jensen, diciembre de 1985, 1-6.

Rubial, Antonio, "Las metáforas del cuerpo en la religiosidad medieval", en Historiae variae, vol. 1, México, Universidad Iberoamericana, 1983, 105-120.

SCHILler, Reinhard, Remedios naturistas de Santa Hildegarda, Barcelona, Tikal Ediciones, s/f.

Sendebar, María Jesús Lacarra (ed.), Madrid, Cátedra, 1989. 
